Vol. LXVI 2015

\title{
NEURAL NETWORKS USED IN THE EVALUATION OF POWER QUALITY
}

\author{
VOLOSCIUC Sorin Dan \\ Faculty of Engineering, Department of Computer Science and Electrical Engineering, \\ Lucian Blaga University of Sibiu, Romania, sorinvolo@yahoo.com
}

\author{
DRAGOSIN Monica \\ FDEE Electrica Distribution Transilvania South, SDEE Sibiu, Romania, monica.dragosin@electricats.ro
}

\begin{abstract}
Monitoring the quality indicators at the interface nodes between the distribution operator and the industrial users is extremely important in order to provide the electric power quality standard level. The power quality has a significant effect on the economic indicators of the distribution network and represents an essential parameter in order to evaluate the performances of the network. The first part of the paper aims to identify some disruptive consumers in the system and the simultaneous measurement of the consumers in order to highlight the effects of the disturbances on the network and on the other consumers of the powers in the system. In the second part of this paper, a program for classifying the data recorded, as result of the monitoring of the power quality is developed. Final part contains conclusion a proposal for some measures in order to align all the quality indicators within the permissible values.
\end{abstract}

Key words: power quality, electromagnetic disturbance, quality indicators, monitoring power quality, neural network

\section{Introduction}

Power quality has been treated as a prominent issue which demands utilities to deliver good quality of electrical power to end users especially to industries having sensitive equipment. Effective monitoring programs are important for power reliability assurance for both energy providers and customers. Voltage sags, harmonics, interruptions, high-frequency noise, etc., are the most important power quality problems which are seen in the industrial and commercial installations. Solving these problems require power quality monitoring and analysis.

In many cases, the phenomena associated with the power quality appear and disappear randomly. Therefore, it is necessary that monitoring of the power quality to be carried out for a long enough period of time. There are several reasons for monitoring the power quality. The most important reason is the economic damage caused by electromagnetic phenomena as a result of the failure or malfunctioning of the sensitive equipment in the industry.

Ideally, a full monitoring program should be used to characterize the performance of an entire system, i.e. every load bus should be monitored. Such a monitoring program is not economically justifiable and only a limited set of buses can be chosen for a monitoring program. Optimal decisions regarding the number of meters and their locations are needed so that the number of meters is minimized without missing any essential information.

\section{The analysis of the recorded data}

Within this study, there observed power quality indicators based upon the recorded data in representative nodes of a distribution network belonging to Electrica Transilvania South Sibiu Subsidiary.

Seven mobile PQ analyzers were deployed in an industrial area supplied by SDEE Sibiu distribution network during one week. Simultaneous power quality monitoring was performed for a group of industrial users supplied from the Distribution Point located in Sibiu West Industrial Park supplied from Aeroport 110/20kV substation.

Propagation of the electromagnetic disturbances in the studied network area is also one of points $f$ interest. The electromagnetic disturbances occurred in network spread along distribution lines. Those disturbances can be identified in different locations, having the same or different characteristics than those existing at the point of emergence. 


\subsection{Study Area Description}

Figure 1 shows a portion from Medium Voltage (MV) distribution network. PQ Equipments were installed in locations highlighted with numbered circles.

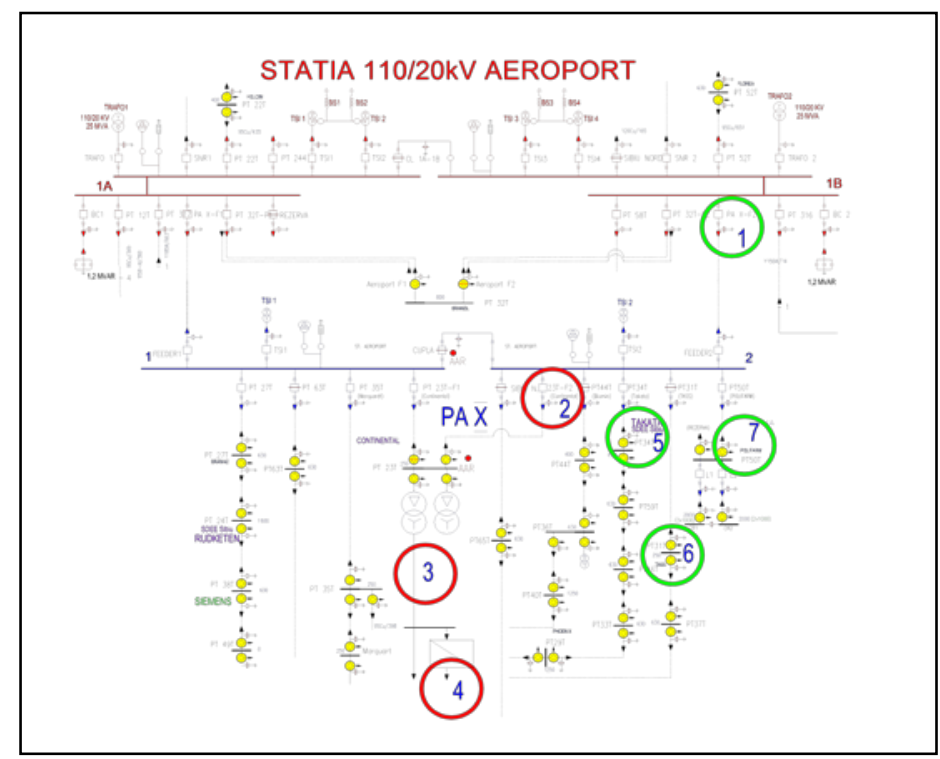

Figure 1: Normal operating power system $P A X$

First PQ analyzer was installed in Feeder PA X bay in Aeroport substation which is the main power supply for the industrial area. In PA X Distribution Point PQ Analyzer number two was installed at Medium MV in the Common Coupling Point (CCP) for one of the largest customer in that area: Continental Automotive Systems plant. Third and fourth PQ analyzers were installed inside one of customer's own transformer station on Low Voltage (LV) side of transformer 1 and on the output of one $1000 \mathrm{kVA}$ inverter. The purpose of this cluster of PQ equipments was to determine the influence of disturbances produced on LV level by a large inverter on power quality parameters at CCP. Fifth, sixth and seventh PQ equipments were installed at neighbouring industrial customers: SC Takata SRL, SC Polipharma Industries SRL and SC TASS SRL.

SC Continental Automotive Systems SRL is supplied in normal operation from the 2'nd busbar section of PA X, through an $20 \mathrm{kV}$ underground cable $1 \mathrm{~km}$ in length. Backup power is supplied by the 1st busbar section of PA X. The simultaneously absorbed power $\mathrm{P}_{\mathrm{sa}}$ is $5300 \mathrm{~kW}$.

SC Takata SRL is supplied by the PA X second busbar section, through an $20 \mathrm{kV}$ underground cable $0,5 \mathrm{~km}$ in length, $\mathrm{P}_{\mathrm{sa}}$ is $2400 \mathrm{~kW}$

SC Polipharma Industries SRL Supplied by the second bars sector of the PA X, through an 20kV underground cable $1,5 \mathrm{~km}$ in length $\mathrm{P}_{\mathrm{sa}}$ is $1700 \mathrm{~kW}$.

SC TASS SRL Supplied by the second bars sector of the PA X, through an $20 \mathrm{kV}$ underground cable $1,8 \mathrm{~km}$ in length, $\mathrm{P}_{\mathrm{sa}}$ is $200 \mathrm{~kW}$.

Consumers: equipment and assembling line, chillers, efficient lighting system, computers, sewing machines, pressing.

\subsection{Power quality equipments}

The measurements have been performed using the following devices:

- four Chauvin Arnoux CA 8335 (green circles in figure 1) and

- $\quad$ three Fluke 435 (red circles in figure 1).

The PQ monitors were installed on the secondary windings of measurement current and/ or voltage transformers. Currents and the voltages that supply the measurement groups of the industrial users were used.

\subsection{The parameters monitored were:}

- RMS values for voltage and current on three phases;

- $\quad$ flicker severity indices for each phase $P_{l t+}$;

- voltage sags and short-term interruptions;

- values for the harmonic voltages and for the harmonic currents and $T H D_{U}$ and $T H D_{I}$

- values for the voltage unbalance factor $k_{n u}$ 


\section{Power quality analysis}

Voltage : In figure 2 is presented the values obtained for voltage; for each phase voltage values stayed within admissible limits and no event occurred. Table 1 show the maximum and minimum values for voltage (rms) recorded on each phase, for locations monitored:

Table 1: Minimum and maximum voltage values

\begin{tabular}{|l|c|c|c|c|c|c|}
\hline \multirow{2}{*}{ Locaţion } & \multicolumn{3}{|c|}{ Maximum values [kV] } & \multicolumn{3}{c|}{ Minimum values [kV] } \\
\cline { 2 - 7 } & $\mathbf{U}_{\mathbf{1}}$ & $\mathbf{U}_{\mathbf{2}}$ & $\mathbf{U}_{\mathbf{3}}$ & $\mathbf{U}_{\mathbf{1}}$ & $\mathbf{U}_{\mathbf{2}}$ & $\mathbf{U}_{\mathbf{3}}$ \\
\hline Aeroport Substation & 20,46 & 20,58 & 20,46 & 20,22 & 20,14 & 20,01 \\
\hline Continental Automotive Systems & 20,39 & 20,58 & 20,51 & 19,99 & 20,17 & 20,09 \\
\hline Takata & 21,24 & 20,50 & 20,42 & 19,80 & 20,10 & 20,00 \\
\hline Polipharma Industries & 20,64 & 20,60 & 20,46 & 20,24 & 20,16 & 19,98 \\
\hline TASS & 20,62 & 20,56 & 20,46 & 20,18 & 20,14 & 20,20 \\
\hline
\end{tabular}

Total harmonic distortion of voltage THDu, the voltage unbalanced factor $k_{n u}$, and the flicker long time indicator $P_{l t}$

During the monitored interval the values of $T H D u$, the flicker long time indicator $P_{l t}$ and the voltage unbalanced factor $k_{u n}$ fall within factor fell within the admitted limits. Maximum values recorded are shows in Table 2. Figure 3 represents the values obtained for total harmonic distortion of voltage,during the study period and Figures 4 and 5 are presenting the registered values of the flicker severity indicator on long-term $P_{l t}$ and the negative unbalance voltage factor $k_{n u}$

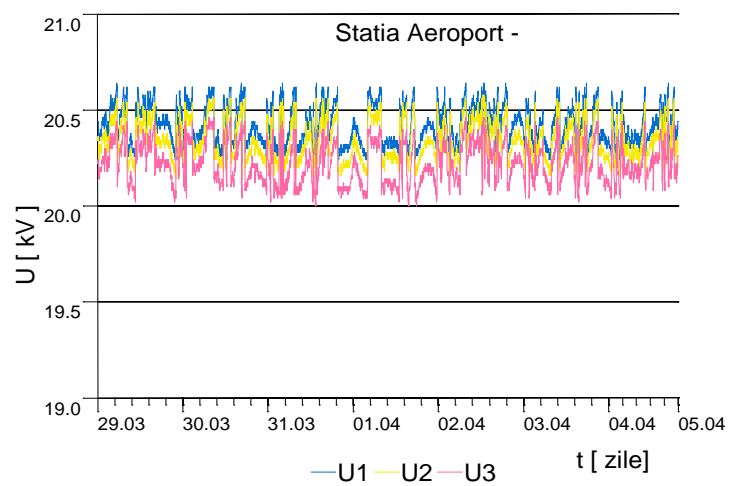

Figure 2: Registered values of the voltage

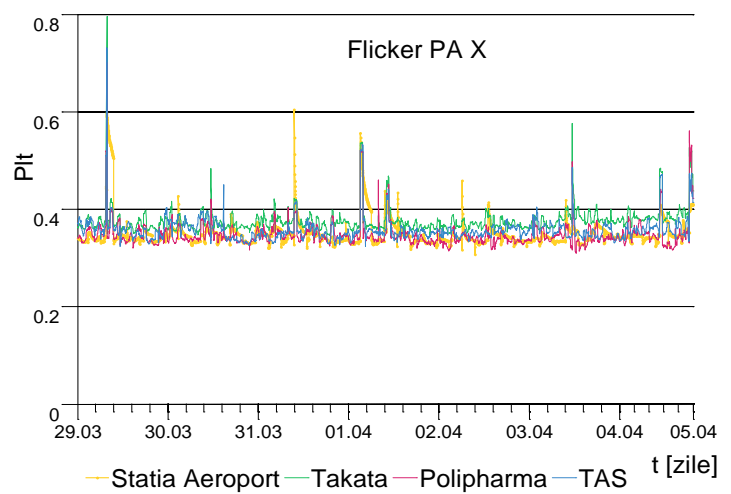

Figure 4: Registered values of flicker $P_{\mathrm{lt}}$

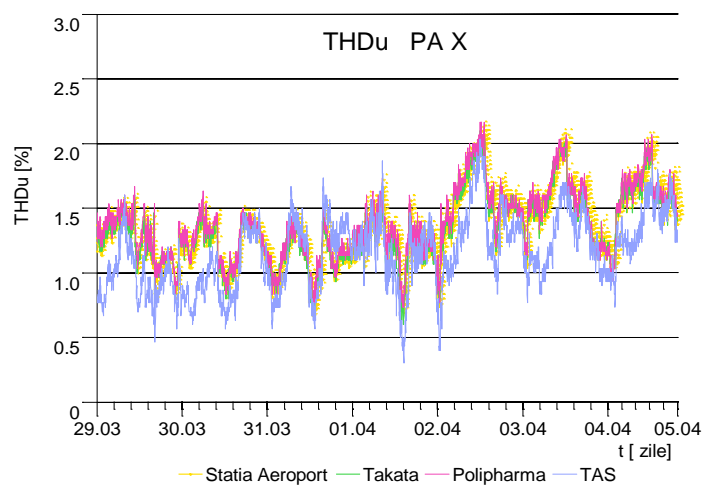

Figure 3: Voltage $\mathbf{T H D}_{\mathrm{U}}$ values record

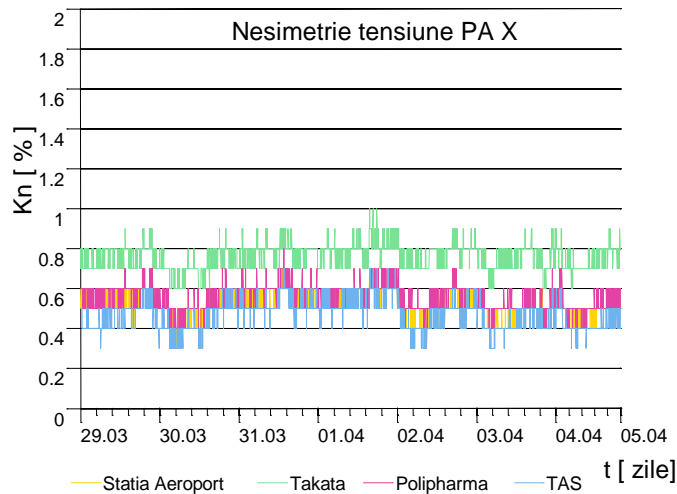

Figure 5: Voltage unbalanced factor $\mathbf{k}_{\mathrm{nu}}$

Table 2: Maximum values THDu, $P_{l t}, k_{n u}$

\begin{tabular}{|l|c|c|c|c|c|}
\hline \multirow{2}{*}{ Location } & \multicolumn{5}{|c|}{ Maximum values [\%] } \\
\cline { 2 - 6 } & THDu $_{\mathbf{1}}$ & THDu $_{\mathbf{2}}$ & THDu $_{\mathbf{3}}$ & $\mathbf{P}_{\mathbf{I t}}$ & $\mathbf{k}_{\mathbf{n u}}$ \\
\hline Aeroport Substation & 2,1 & 2,1 & 2,1 & 0.79 & 0.7 \\
\hline Continental Automotive Systems & 2,0 & 2,3 & 2,2 & 1.0 & 0.77 \\
\hline Takata & 2,0 & 2,2 & 2,2 & 0.95 & 0.92 \\
\hline Polipharma Industries & 2,0 & 2,1 & 1,9 & 0.89 & 0.80 \\
\hline TASS & 2,1 & 2,1 & 1,9 & 0,86 & 0,7 \\
\hline
\end{tabular}




\section{Neural networks for the identification of the disturbances in the West Sibiu area.}

The practical solving of a complexity of problems in the field of electrical engineering has shown that the mostly useful and the mostly used artificial intelligence techniques are the expert systems (SE), the fuzzy logic (LF), the artificial neural networks (RNA) and the genetic algorithms (AG). In parallel, new techniques of optimization, such as optimization through swarms of particles (Particle Swarm Optimization-OSP) or ant colonies (Ant Colony Optimization-ACO) have been developed and implemented.

The neural networks are beneficial in the case when, few decisions have to be made based on a large amount of data and, an optimal solution to a problem of optimization, it is necessary to be found quickly. The neural network is extracting the information that was presented in the training stage and subsequently uses it within the practical applications where it is used.

The neural network used for the identification of the disturbances in the West Sibiu area is a feedforward artificial neural network with four layers, as shown in the Figure 6.

The networks with the recognition pattern are the feed-forward networks which can be trained in order to classify the entries according with the target groups. The target data for the networks with the recognition pattern are consisting in vectors with all the values zero, except the element $i$, whose value is 1. With the help of the neural network presented above, the data recorded as the result of monitoring of the power quality to the group of the large industrial consumers in the industrial area from West of Sibiu , were classified. The neural network is trained with the back propagation algorithm of the scaled conjugate gradient (scaled conjugate gradient Back Propagation-BKP) using a dedicated Toolbox from Matlab, respectively, the Neural Network Pattern Recognition Tool

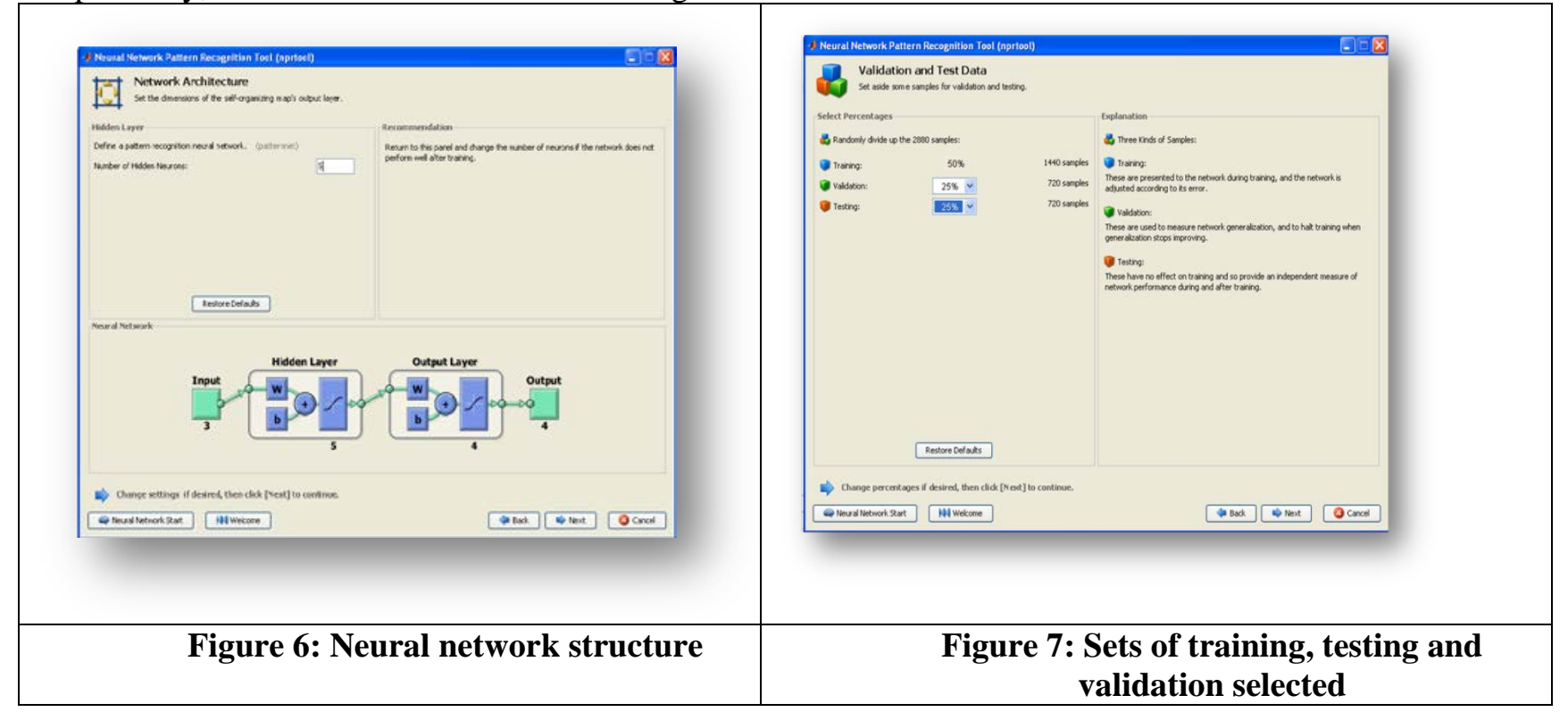

The input data for the network are represented by the values recorded in the Aeroport substation (Feeder PA X) and in PA X Distribution Point for the following consumers: SC Continental Automotive Systems SRL, SC Takata SRL and SC Polipharma Industries SRL.

The input vector consists in the values recorded, on the three phases, for the following parameters: voltage, total harmonic distortion of voltage THDu, the voltage unbalanced factor and the flicker long time indicator Plt

The target vector is calculated based on some limit values that are settled in the Performance Standard for these sizes, the neural network has to identify the emergence of some disturbances, and the existence of some measured quantities that are not framing in the limits that were imposed. The vector contains four elements, representing the number of the disturbances classes under analysis, respectively, voltage variations, the overflow of the level of the harmonic content, the overflow of the level of the flicker and the unbalance of the voltages' system. Of the four elements, there is only one that has the value one, the one that describes the class of the disturbances under surveillance; the rest have the value zero. The four variants of the output vector and the threshold values taken in consideration, named th, are:

- for the voltage variations: the target vector is $\left[\begin{array}{llll}0 & 0 & 0 & 1\end{array}\right]^{\mathrm{T}}$, and $t_{h}= \pm 10 \%$;

- for the total harmonic distortion of voltage: the target vector is $\left[\begin{array}{llll}0 & 0 & 1 & 0\end{array}\right]^{\mathrm{T}}$, with $t_{h} \leq 8 \%$;

- for the flicker effect: the target vector is $\left[\begin{array}{llll}0 & 1 & 0 & 0\end{array}\right]^{\mathrm{T}}$, with $t_{h}<1 \%$;

- for the unbalance of the voltages' system: target vector is $\left[\begin{array}{llll}1 & 0 & 0 & 0\end{array}\right]^{\mathrm{T}}$, with $t_{h} \leq 2 \%$. 
For the implementation of the classifications with the artificial neural network having pattern recognition, within the Matlab programming-simulation environment, the sets of training, testing and validation were first selected. When all the network settings are defined, the training of the network begins. The process stops automatically when the generalization ability becomes insignificant. A perceptible increase of the validation samples in the average quadratic error, respectively, the reach of the minimum threshold set for it are marking this moment.

The results obtained after the training of the network are represented by a confusion matrix Figure 8, where the lines and the columns 1 to 4 represent the four classes of the disturbances under surveillance, such as:

a) Class 1: voltage variations;

b) Class 2: the distortion of the voltage expressed by the distortion factor $\mathrm{THD}_{\mathrm{U}}$;

c) Class 3: the flicker effect expressed by the $\mathrm{P}_{\mathrm{lt}}$;

d) Class 4: the unbalance of the voltages' system

SC Continental Automotive System

SRL

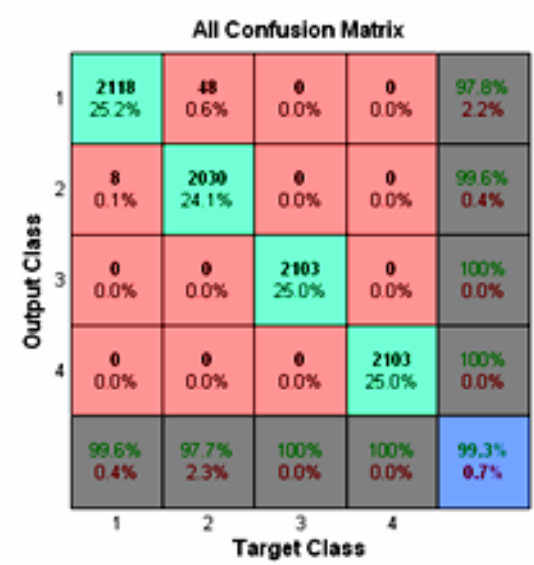

SC Takata SRL

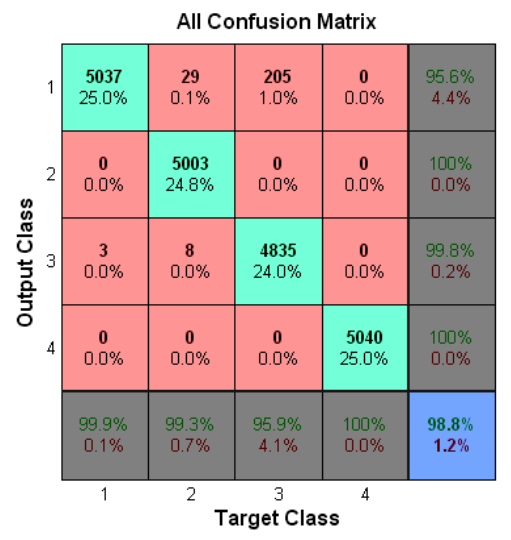

SC Polipharama Industries SRL

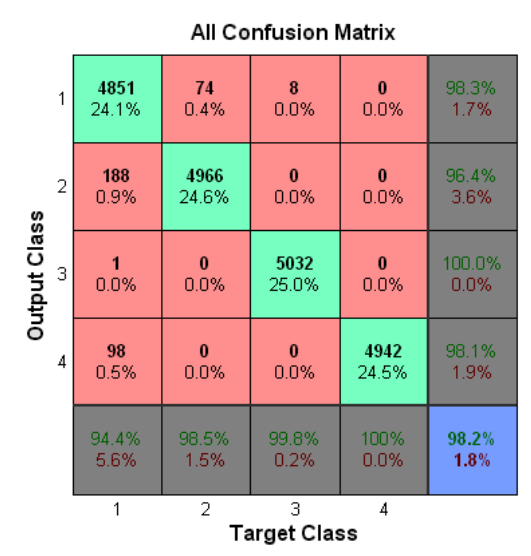

Aeroport Substation 110/20kV

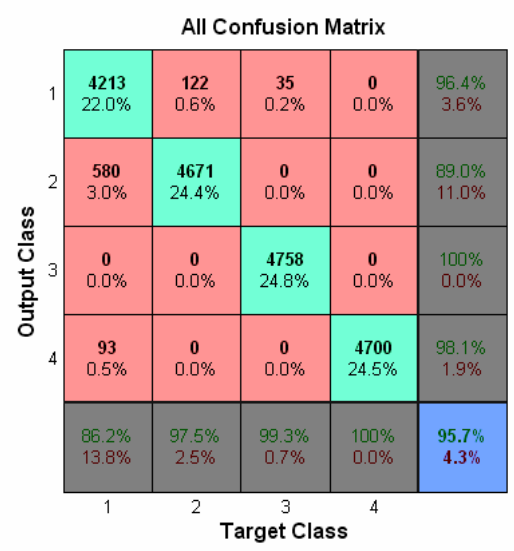

Figure 8: The confusion matrix for all data

The confusion matrix for the data set calculates the accuracy and the errors of the classification associated with this set. For each series of the data that was used, the accuracy is shown in the last column (sensitivity is with green and specificity is with red).

The diagonal (coloured in green) indicates, for each parameter, how many windows have been correctly recognized and the percentage from all the windows (representing the other positions).

The red boxes represent the errors, the number of the windows that have been wrongly recognized and their percentage of the total data set. The last line calculates, for each column, what percentage is correctly classified (in green) or wrongly classified (in red) from the total number of the windows that are classified in that column, meaning the accuracy of the neural network classifier (the percentage of the positive predictions that are correct). 
The process of classification was reviewed several times, for the same input data but modifying the number of the neurons in the hidden start or the percentages of the training, testing, and validation sets. In this paper are presented the best results obtained with the classification system based on the use of RNA. The process of classification with the neural networks has been carried out for all the consumers under monitoring from the West Industrial area. In each case, the input vector and the target vector were determined, then the training of the network was carried out. The total confusion matrix obtained is shown in the Figure 8 and the final results are summarized in the Table 3.

Table 3: The final results of the classification

\begin{tabular}{|l|c|c|c|c|c|}
\hline Location & Voltage & $T H D u$ & $P_{l t}$ & $k_{n u}$ & Total \\
\hline Aeroport Substation & 96,4 & 89,0 & $\mathbf{1 0 0}$ & 98,1 & 95,7 \\
\hline Continental Automotive System & $\mathbf{9 7 , 8}$ & 99,6 & $\mathbf{1 0 0}$ & $\mathbf{1 0 0}$ & $\mathbf{9 9 , 3}$ \\
\hline Takata & 95,6 & $\mathbf{1 0 0}$ & 99,8 & $\mathbf{1 0 0}$ & 98,8 \\
\hline Polipharma Industries & 98,3 & 96,4 & $\mathbf{1 0 0}$ & 98,1 & 98,2 \\
\hline
\end{tabular}

The results after the classification are: SC Continental Automotive System : the total percentage of 99,3\%. indicates that during the monitoring period, the recorded data for all the indicators under analysis are the closest ones to the thresholds. If the analysis is carried out separately for each quality indicator under monitoring, the following aspects are observed:

- voltage variations - the largest percentage, 97,8\% was obtained at SC Continental Automotive System SRL

- the distortion factor THDu - the largest percentage, $100 \%$ was obtained at SC Takata SRL

- the flicker effect $P_{l t}$ - the percentage of $100 \%$ was obtained in 3 locations: Aeroport Substation, SC Continental Automotive System SRL and SC Polipharma Industries SRL

- the unbalance of the voltages' system $k_{n u}$ - the largest percentage, $100 \%$ was obtained at SC Continental Automotive System SRL and SC Takata SRL.

\section{Conclusions}

Monitoring the quality indicators at the interface between the network operators and the users and supervising the framing of disturbances within the allocated limits, represent actions that have an important role to ensure the proper functioning of the power supply, the limitation of the disturbance background in the network and to ensure the level of the quality for all users of the system.

The power quality has a significant effect on the economic indicators of the distribution network and represents an essential parameter in order to evaluate the performances of the network.

The analysis of the electric power quality problems is important in order to know the network configuration, the industrial user profile and the type of the electromagnetic disturbances created by the industrial user.

The presented neural network classifier may be used in processing a huge amount of data collected by monitoring the distribution network and ensures the identification of the disturbances chosen by the operator. The developed algorithm was tested, with good results on the data recorded during the measuring campaign to identify four types of disturbances.

\section{References}

- Mircea, Chindriş., Anca, Miron., Transmiterea perturbaţiilor electromagnetice conduse în sistemele electroenergetice, Editura Casa Cărţii de Ştiinţă, Cluj Napoca, (2009)

- Carmen, Golovanov Ionescu., Măsurarea mărimilor electrice în sistemul electroenergetic Editura Academiei si Editura Tehnică Bucureşti (2009)

- Nicolae, Golovanov., Petru, Postolache.,Toader., Calitatea şi eficienţa energiei electrice, Editura AGIR (2007)

- Ioana, Farkas., Rodica, Doran., Testing fast trening algorithms for artificial neural networks with feedforward propagation, Simpozionul SEET, mai 2009, Novice Ins

- Rodica, Doran., Ioana, Farkas., Classification of a number of postures/activities based on unsupervised learning algorithms, Quality and Innovation in Engineering and Management, Cluj-Napoca, 2011

- Ahmad Asrul Ibrahim, Azah Mohamed "Optimization Methods for Optimal Power Quality Monitor Placement in Power Systems", IEEE Transactions on Power Delivery ,Volume 4, Number 1, March 2012

- ***Standardul de performanţă pentru serviciul de distribuţie e energiei electrice ANRE 2007

- ***Compatibilitate electromagneică (CEM) Partea 4: Tehnici de încercare şi de măsurare. Secţ 30. Metode de măsurare a calităţii energiei SR CEI 61 000-4-30/2008 